\title{
Camel Calf Husbandry Practices and Health Problems in Fafem Zone, Ethiopian Somali Region
}

\author{
Abdi Hassan Rirash, Befekadu Urga Wakayo* and Hassan Abdi \\ College of Veterinary Medicine, Jigjiga University, Jigjiga, Somali Regional State, Ethiopia
}

\begin{abstract}
Background: Calf mortality represents a major production and livelihood constraint in the Somali region of Ethiopia. Disease was incriminated as a major underlying cause. However, epidemiology of major calf diseases in the region is not well documented.

Methods: Cross-sectional study was conducted between October 2014 and March 2015 to explore major camel calf ( $\leq 1$ year) diseases and associated drivers in Gursum and Kebribeya districts of Somali region. Participatory survey of calf husbandry and diseases was conducted on 51 camel holdings. Clinical and laboratory examination of health problems was performed on 189 camel calves

Results: Camel holding size showed inter-herd and geographical variability. Calves accounted to $13.5 \%$ of average camel herds. Peak camel calving period was between October and March. Calving usually (86.3\%) occurred from late-afternoon to night hours. Majority $(90.2 \%)$ of producers restricted early colustrum intake and $78.4 \%$ restricted milk suckling after 1 month. Further suckling restriction, introduction of green forages and herd mixing were practiced after 3 months of age. According to producers young ( $<6$ months) calves were commonly affected by diarrhea (100\%), orf (92.2\%), respiratory illness (33.3\%), plant poisoning (25.5\%) and camel pox (7.9\%). Major problems reported in older (6-12 months) calves include; mange $(94.1 \%)$ and tick $(86.3 \%)$ infestations, ring worm (62.7\%); camel pox (56.9\%); trypanosomosis (51\%) and respiratory illness (9.8\%). Calf health investigation detected Sarcoptes scabie var cameli $(16.4 \%)$ and mixed tick $(H$. dromedary, $H$. truncatum \& R. pulchelis) $(12.7 \%)$ infestation, diarrhea (3.7\%) and respiratory illness (1.1\%). Mange infestation and plant poisoning were higher in Gursum district whereas tick infestation was higher in small herds.
\end{abstract}

Conclusion: Camel calves were exposed to different debilitating and/or life threatening diseases. Potential risk factors include; inadequate colustrum feeding, under-nutrition, and premature exposure to endemic pathogens, vectors and harmful plants. Further epidemiological and intervention studies are recommended.

Keywords: Calves; Camel; Colustrum; Diseases; Ethiopia; Husbandry; Poisoning

\section{Introduction}

The one humped camel (Camelus dromedarius) is multi-functional farm animal species uniquely adapted to arid and semi-arid zones. Ethiopia is home to an estimated 2.4 million camels found mainly in the arid to semi-arid regions [1]. For pastoralist and agro-pastoralist communities residing in these harsh environments, the camel represents a vital source of food, income and other services [2,3]. Developing camel production could offer a suitable alternative for meeting chronic and often escalating challenges of food insecurity in eastern Africa [4]. However, performance and hence livelihood and economic contribution of regional camel populations is very low owing to complex constraints such as; poor husbandry systems, widespread feed shortage and diseases, inadequate health and extension services, etc. [5].

Under east African pastoral/agro-pastoral production systems, heavy pre-weaning calf mortality represents a major impediment to camel herd growth and production potential. This is further compounded by low reproduction rates attributed to delayed maturation, long gestation period and long inter-calving intervals [6-8]. High camel calf mortality rate of up to $53.1 \%$, before 1 year, has been reported in eastern Ethiopia [9]. Widespread diseases, malnutrition due to household competition for milk and predators accounted for the major share of these losses $[5,6,10]$ Studies in east Africa indicate that camel calves are susceptible to a wide range of diseases including; diarrhea, pox, contagious ecthyma, contagious skin necrosis, pneumonia, tick and mite infestations and internal parasites [11-13]. Withholding colostrum from neonates due to belief of many pastoralists that it causes fatal scouring was an important risk factor to heavy disease losses $[4,14]$.

Epidemiological information on magnitude, causes and important risk factors of major camel calf diseases in the Somali region of Ethiopia is, at best, patchy. Therefore, the study attempted to describe major camel calf health problems and associated husbandry constraints in selected districts of the Ethiopian Somali region.

\section{Methodology}

\section{Study area}

The study was conducted in Gursum and Kabribayah Districts of Fafen zone in the Ethiopian Somali Region. The altitude of Fafem zone

*Corresponding author: Befekadu Urga Wakayo, College of Veterinary Medicine Jigjiga University, Jigjiga, Somali Regional State, Ethiopia, Tel: +2510911731254; Fax:+2510257755947/76; E-mail: fikeurga@gmail.com

Received June 09, 2017; Accepted July 19, 2017; Published July 20, 2017

Citation: Rirash AH, Wakayo BU, Abdi H (2017) Camel Calf Husbandry Practices and Health Problems in Fafem Zone, Ethiopian Somali Region. J Vet Sci Technol 8: 456. doi: 10.4172/2157-7579.1000456

Copyright: @ 2017 Rirash AH, et al. This is an open-access article distributed under the terms of the Creative Commons Attribution License, which permits unrestricted use, distribution, and reproduction in any medium, provided the original author and source are credited. 
ranges between 1,500-1,800 m.a.s.l and the topography ranges from of flat to gentle slope, hilly and mountainous. The average annual rainfall ranged from $300 \mathrm{~mm}$ to $500 \mathrm{~mm}$ and average monthly temperature ranges 16 to $20^{\circ} \mathrm{C}$. Fafem zone is divided into three separate Food Economy Zones (FEZs), namely, sedentary agriculturalists (9.1\%)., agro pastoralists $(56.8 \%)$ and pastoralists (34.1\%) [15]. It has eight administrative districts, namely Jigjiga, Kebribeyah, Harshin, Babile, Awbare, Gursum, Tullu Guled and Gololchen. Of these, Gursum and Kebribeya districts were selected for the study by considering accessibility of camel herds and representation of different production systems in the zone.

\section{Study design}

Participatory survey of camel producers and clinical examination of corresponding camel calf ( $<12$ months) stocks was conducted Gursum and Kebribeya districts from October 2014 to March, 2015. The study aimed to identify major health problems affecting camel calves and to describe corresponding animal, husbandry, and environment related risk factors in the study area.

\section{Sampling}

A total of 8 kebele's were selected by random lottery method from a sampling frame of all Kebele's in the two study districts. Subsequently, camel producers and corresponding calf stocks were sampled systematically by including every $5^{\text {th }}$ consenting household during field visit to selected kebele's. Taking logistic constraints in to account, a total of 51 camel rearing households and 189 calves aged $\leq 12$ months were included in the study.

\section{Data collection}

Participatory interview survey was conducted on selected camel producers. Information pertaining to camel holding pattern, age related calf husbandry practices (early colustum feeding, milk suckling, feeding forages, and housing/herding), and priority calf health problems was recorded using a semi-structured format prepared for the specific purpose. Local disease names were cross-checked against reported symptoms to confirm disease identity.

Calves (aged $\leq 12$ months) in selected camel holdings were examined e for clinical health status based on history and physical examination. Local disease names and corresponding clinical symptoms were triangulated to establish identity of calf health problems as outlined below.

- Diarrhea/Scour: Watery off smelling feces and soiled perineum in recently born calves. Leads to drastic weight loss, sunken eye and often death.

- Contagious ecthyma/Orf: Small swelling and hard scabs around mouth sometimes depressed and avoid feeding.

- Respiratory illness: Cough and nasal discharge, progressive loss of condition.

- Plant poisoning: Sudden death following grazing in rangelands.

- Camel mange: Itching, reddening of skin, hair loss and crusts on neck shoulder abdomen and inside of legs. Affected animals are sometimes reluctant to feed properly and gradually lose body condition.

- Tick infestation: Visible parasites usually inside of thighs and tail base, progressive lose body condition in severe cases.
- Ring worm/Dermatophytes: Circular hair loss around head neck and back without any sign of itching.

- Camel pox: General illness, small soft swellings mainly around eyes and head, nasal and/or ocular discharge enlarged lymph nodes.

- Camel trypanosomosis: Progressive weight loss even during or shortly after rainy season and edema of lower body.

Visible Ticks were manually collected from their attachment sites and placed in a universal bottle pre-filled with $70 \%$ alcohol. Skin scraping was collected from suspected cases of mange/mite infestation (exhibiting scales, crusts, alopecia and/or itching) in universal bottles pre-filled with $10 \%$ formalin according to [16]. All sample containers were properly labeled (household and animal id \#, date, specimen type) and transported in an ice box to laboratories at College of Veterinary Medicine - Jigjiga University for analysis.

Tick species were identification based on standard procedure and morphological criteria as described by [17]. Skin scrapings were liquefied by adding $\mathrm{KOH}$ on petridish and examined under low power microscopy to identify species using a morphological key [18].

\section{Statistical analysis}

Participatory survey, clinical investigation and laboratory analysis data were entered on Microsoft Excel spreadsheets and analyzed using SPSS - 20 (SPSS inc). Numerical and categorical data were summarized using descriptive statistics (Mean \pm SE and percentage (\%)), frequency tables and graphs. Chi square test and comparison of means (independent-t and ANOVA tests) were used to draw inferential contrasts on camel holding patterns, calf rearing practices and health problems. Camel/calf holding sizes and calf age estimates were not normally distributed. Therefore, contrasts were made using natural logarithm (Ln) and reported in back transformed values. Statistical significance was determined at $\mathrm{p}<0.050$.

\section{Results}

\section{Camel holding pattern}

Total herd size varied from 7 to 90 heads of camel with an average of $24.44 \pm 1.08 \mathrm{camels} / \mathrm{herd}$. Meanwhile, the size of calf stocks in herds varied from 1 to 11 and averaged $3.27 \pm 1.07$ calves/herd. Average total herd camel $(\mathrm{p}=0.016)$ and calf holdings $(\mathrm{p}=0.002)$ sizes were higher in Gursum (31.6 \pm 3.14 camels and $4.23 \pm 0.34$ calves per herd) compared to Kebribeya $(22.45 \pm 2.7$ camels and $2.85 \pm 0.32$ calves per herd) district.

\section{Calving calf rearing practices}

Calving trends: According to surveyed camel producers, camels usually calved in late afternoon - evening hours $24(47.1 \%)$ or during night time 20 (39.2\%), and less commonly in the morning 7 (13.7\%). Meanwhile, the calving month of calculated from reported calf age estimates showed higher $(\mathrm{p}<0.050)$ calving frequency during the long (Jilal) dry season (October -March) compared to the short (Haga) dry season as well as the Dira Gu (April-May) and Karan Gu (AugustSeptember) rainy periods (Figure 1a). Calving outside the long-dry season was comparatively more frequent $\left(\mathrm{X}^{2}=7.8, \mathrm{p}=0.039\right)$ in Gurusm (34.8\%) than Kebribeya (17.5\%) district (Figure 1b).

Colustrum provision: Only 5 (9.8\%) of surveyed camel producers allowed full suckling of colustrum by the newborn calf on its first day of life. Remaining producers restricted initial colustrum intake by 
Citation: Rirash AH, Wakayo BU, Abdi H (2017) Camel Calf Husbandry Practices and Health Problems in Fafem Zone, Ethiopian Somali Region. J Vet Sci Technol 8: 456. doi: 10.4172/2157-7579.1000456

Page 3 of 6

$\mathbf{a}$

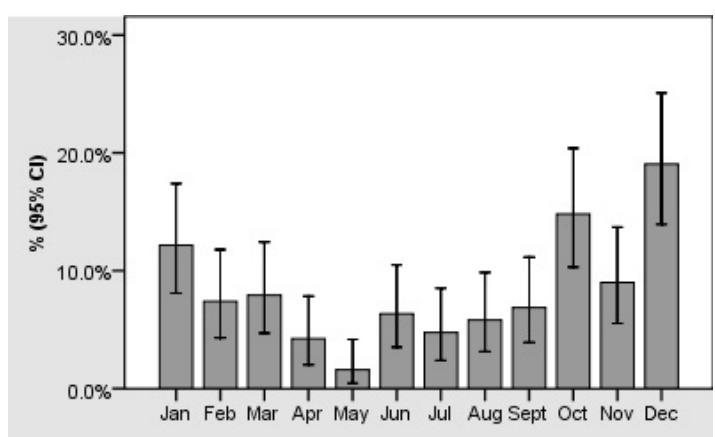

b

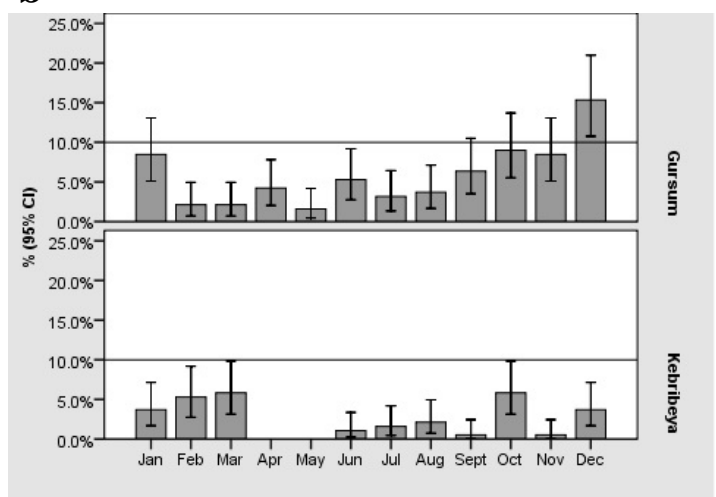

Figure 1: Annual distribution of camel calving months (\%); total (a) and according to study district (b).

limiting suckling $28(54.9 \%)$ or partially milking colutsrum before the calf suckles 18 (35.3\%). The practice was always associated to risk of fatal scouring. Frequency of full suckling, restricted suckling and milking - suckling - hand feeding in Gursum (9.7\%, 51.6\% and 38.7\%, respectively) and Kebribeya ( $10 \%, 10 \%$ and $80 \%$, respectively) districts showed variation $\left(\mathrm{X}^{2}=9.7, \mathrm{p}=0.003\right)$.

Feeding and watering: All participants reported that calves were given only milk during the $1^{\text {st }}$ months and milk plus water until 3 months of life thereafter. During the $1^{\text {st }}$ month of life daily milk suckling frequency ranged from $\geq 5(94.1 \%)$ to $\leq 4(5.9 \%)$ per day. Until the $3^{\text {rd }}$ month, $21.6 \%$ and $78.4 \%$ producers allowed $\leq 5$ and $\leq 3$ suckling per day, respectively. After the $3^{\text {rd }}$ month, suckling was reduced to $3(7.8 \%)$ and $\leq 2(92.2 \%)$ times per day. Producers gradually initiated hand feeding fresh-cut green grass/forages $12(23.6 \%)$ or grazing on nearby range plants $39(76.5 \%)$ after latter age.

Housing/Herding: Majority of producers 42 (82.4\%) kept the newborn camel calf with its dam around homesteads during day and in separate night enclosure until 3 months of age and $9(17.6 \%)$ started mixing neonates with older calves before latter age. After 3 months of age, all mixed newborn calves with older immature herd mates for daytime nearby range foraging and/or in night calf enclosures.

\section{Calf health problems}

Participatory survey: Overall, surveyed camel producers identified nine major calf health problems showing (except for respiratory illness) age-group related variations. Accordingly, the most frequently reported young camel calf ( $<6$ months) problems were; diarrhea 51 (100\%), contagious ecthyma/orf 47 (92.2\%), respiratory illness 17 (33.3\%), plant poisoning 13 (25.5\%) and camel pox 4 (7.9\%). Meanwhile, mange 48 (94.1\%) and tick 44 (86.3\%) infestations; ring worm/dermatophytes (alopecia and scaliness) 32 (62.7\%); camel pox (general illness plus popular lesions around head) 29 (56.9\%); trypanosomosis 26 (51\%) and respiratory illness 5 (9.8\%) were frequently reported problems in older growing (6-12 months) calves (Figure 2).

Plant poisoning in young ( $<6$ months) calves was only reported in Gursum (38.7\%) district ( $\mathrm{p}=0.001)$. Reporting frequency (RF) of mange/mite infestation was higher $(\mathrm{p}=0.019)$ in Gursum $(100 \%)$ compared to Kebribeya (80\%) district (Figure 3).

Field calf investigation: Examination of camel calves detected 64 (34.9\%) apparent health problems including; Sarcoptes scabie var cameli 31 (16.4\%), tick infestation 24 (12.7\%), diarrhea/scour 7 (3.7\%) and respiratory illness (nasal discharge and recent history of cough) 2 (1.1\%). Tick infestations involves $H$. dromedary 22 (11.6\%), R. pulchelis $19(10.05 \%)$ and $H$. trancatum $16(8.4 \%)$ species mainly as mixed species affections (Table 1).

Mean age (months) of camel calves exhibiting diarrhea was higher $(\mathrm{p}=0.000)$ than that of healthy calves or calves facing tick and mange/mite infestation or respiratory illness (Figure 4). Prevalence of mange/mite infestation was higher in Gursum 28 (21.2\%) compared to Kebribeya 3 (5.3\%) district calf flocks (Table 2). Meanwhile, tick infestation was more prevalent in small $(<25$ camel) $12 / 56(21.4 \%)$ compared to medium (25-50 camels) $8 / 106(7.5 \%)$ or large $(>50$ camels) 4/27 (14.8\%) herds ( $\mathrm{p}=0.037)$.

\section{Discussion}

Overall camel holding pattern showed high variability among

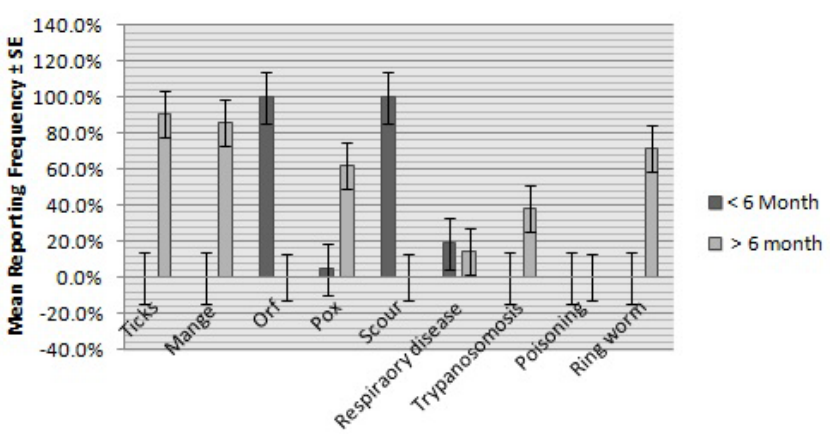

Figure 2: Reporting frequency (RF) of major health problems relative to calf age group.

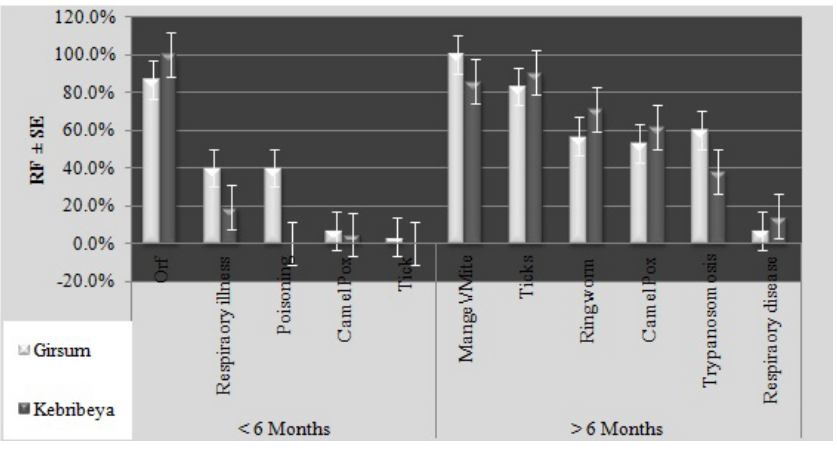

Figure 3: Reporting frequency (RF) of major camel calf health problems according to study districts. 


\begin{tabular}{|l|c|c|}
\hline Tick Species & N & $\%$ \\
\hline$H$. dromedary & 2 & $1.1 \%$ \\
\hline R. pulchelis & 2 & $1.1 \%$ \\
\hline$H$. dromedary $+H$. trancatum & 3 & $1.6 \%$ \\
\hline$H$. dromedary $+R$. pulchelis & 5 & $2.6 \%$ \\
\hline H. dromedary $+H$. trancatum $+R$. pulchelis & 12 & $6.3 \%$ \\
\hline
\end{tabular}

Table 1: Frequency of tick infestation pattern according to species composition

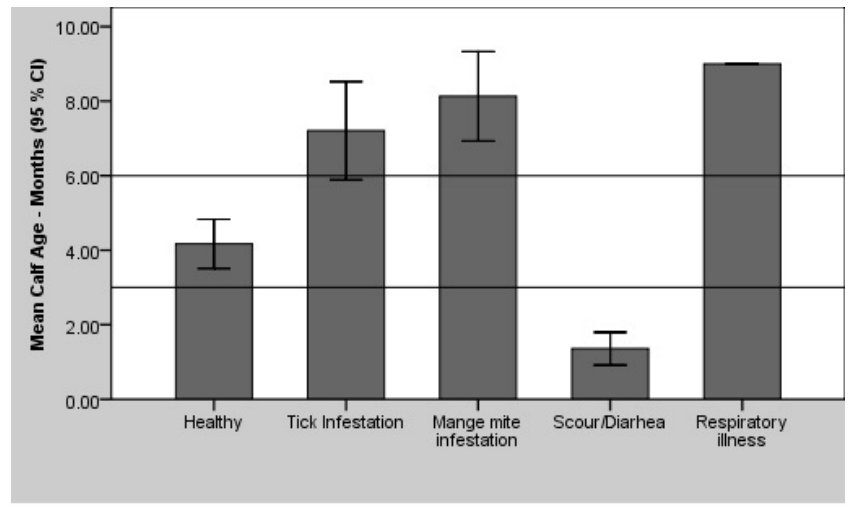

Figure 4: Average age of calves according to health status.

\begin{tabular}{|l|c|c|c|}
\hline \multirow{2}{*}{ Health Problems } & \multicolumn{2}{|c|}{ Districts } & \multirow{2}{*}{ Fishers>p value } \\
\cline { 1 - 3 } & Gursum (132) & Kebribeya (57) & \\
\hline Mange/mite infestation & $28(21.2)$ & $3(5.3)$ & 0.004 \\
\hline Tick infestation & $15(11.4)$ & $9(15.8)$ & 0.261 \\
\hline Diarrhea/Scour & $7(5.3)$ & - & 0.077 \\
\hline Respiratory illness & - & $2(3.5)$ & 0.090 \\
\hline Total & $\mathbf{5 0 ( 3 7 . 9 )}$ & $\mathbf{1 2 ( 2 1 . 1 )}$ & $\mathbf{0 . 0 1 7}$ \\
\hline
\end{tabular}

Table 2: Frequency (n (\%)) of camel calf health problems relative to districts.

households and the average camel herd size was $24.4 \pm 1.1$ animals. This was comparable to average camel herd size of $25.7 \pm 29.8$ previously reported from Somali region of Ethiopia [19]. Calves aged $\leq 12$ months accounted for $13.5 \%$ of average camel holding reflecting slow herd growth rate. This was probably attributed to slow reproduction and/or high calf mortality rates. In agreement, [6] reported that camels in the study area had late ( $>5$ years) first calving and long (around 2 years) inter-calving interval. This was compounded by high pre $(61.5 \%)$ and pos $(33.5 \%)$ weaning calf mortality [20]. Spatial variations in average camel holding size could reflect differences in agro-ecological and market potentials. Gursum district has higher precipitation and vegetation cover as well as better access to milk market chains supplying Jigjiga town and Somali land.

Traditional east African camel pastoralists control breeding time in such way as to ensure calving during growing months as well as year round milk supply [7,21]. Similarly, current findings indicate a seasonal camel calving tendency with higher percentage of camels giving birth between October and January. In the study area, this represents earlier parts of the long Jilal dry season immediately following Karan $(\mathrm{Gu})$ rains [15]. The period offer abundant plant growth and milder weather which favor both milk production and reduces risk of extreme neonatal losses due to extreme weather. Moreover, the next growing period after Dira $(\mathrm{Gu})$ rains (April-May) coincides with age of calf introduction to green forages. Parturition outside the peak calving months was more common in Gursum compared to Kebribeya district which probably reflects longer rain and growing intervals in the former. Meanwhile, $39.2 \%$ of camel calving was reported to occur at night. This complicates timely detection and management of calving difficulty which represents a common problem in the species [21].

Camel calves are born with an immature immune system. So they require immediate passive immune transfer through colustral (firstmilk) IgG intake within 24 hours of birth [22]. In contrast, majority (90.2\%) of producers in the current study restricted early colustrum intake by limiting suckled volumes (54.9\%) or by milking portions of the first-milk before calf is allowed to suckle (35.3\%). The latter practice was frequent in Kebribeya district and could indicate more serious colustrum restriction as it denies any unobserved suckling opportunity in the first 24 hours of life. Camel pastoralists in Somali [10] and Borana [11] areas of Ethiopia and adjacent areas in eastern Africa [4,21,23] were widely recognized for restricting early colustrum intake. In contrast, [20] reported that up to $46.4 \%$ of camel producers in adjacent areas allow full colustrum suckling by camel newborns which could be attributed to difference of production systems covered by the study. In accordance with previous studies [4], the main reason for restricting early colustum intake was a fear of fatal scour. In fact, camel colustrum is known to have powerful laxative effects attributed to its high total protein (15.8-19.5\%) and mineral (1.4-2.8\%) content [24]. However, risk of scour could be mitigated by dividing the optimum colostrum intake in to multiple feeding episodes mainly within 4 hours of birth as recommended for bovine calves [25].

Camel newborns were totally dependent on milk for nutrition during the first 3 months of life. However, milk suckling frequency was substantially restricted by majority of producers $(78.4 \%)$ after the $1^{\text {st }}$ month of life. In addition, after age of 1 month camel producers were reported to limit the number of teats a calf is allowed to suckle using various forms of physical barriers [20]. Widespread practice of suckling frequency and teat access restrictions probably reflect magnitude of calf - human (household/market) competition for milk. Such early milk restrictions hold substantial negative implications to survival and growth of newborn camel calves. Others suggested that conflicting trends of rising consumer demand and stagnantly-low productivity was tipping competition for camel milk against calves and contributing to heavy mortality losses in eastern Africa $[21,26]$.

The age of 3 months was a particularly critical transition phase for camel calves in the study area. At this age, all producers mixed calves with older herd-mates and gradually introduced green forages wherein milk suckling frequency was further restricted by most (92.2\%) producers. Newborn calves are very prone to trauma, predation, poisoning and diseases when prematurely mixed to older animals in rangelands or night enclosures. Experiences from modern bovine farming systems emphasize crucial need of segregating calves by age and maintaining sanitation in housing facilities [25]. In contrast to the current finding, communities around the study area were previously reported to initiate green feeds at younger age of 1 month [20]. Meanwhile, [23] indicated that Somali camel calves in Kenya began grazing at 3-4 months of age which was comparable with the current observation. On the other hand, [7] indicated that, in Ethiopia, camel calves were exclusively fed on milk until the age of 6 months and weaning ensued thereafter. The age and manner of weaning is predicated on existing levels of milk production, consumer demand (domestic and market) and intended use of calves. Early introduction of forage/grazing could pose additional negative pressure on nutrition and health of camel calves having inadequately developed digestive tracts.

According to surveyed producers the diseases commonly affecting camel calves in the study area were; diarrhea, orf, mange and tick infestations, ring worm, camel pox, trypanosomosis, respiratory 
illness and plant poisoning in the given order. These were comparable to range of diseases reported from different areas in Ethiopia [6,7] and neighbouring countries [12,13,23,27]. Cross-sectional field investigation of camel calf ( $\leq 12$ months) diseases detected mange (Sarcoptes scabie var cameli) infestation (16.4\%), mixed tick (H. dromedary, H. truncatum and R. pulchelis) infestation (12.7\%), diarrhea (3.7\%) and respiratory illness (1.1\%). Ecto-parasite infestation and diarrhea were recognized to be the principal camel calf health problems in the study area [20]. A higher prevalence of mange (Sarcoptes scabiei) infestation has been reported for camels aged $\geq 1$ year [28]. Meanwhile, a longitudinal study (covering all major seasons) of camel calf diseases in Borana reported higher prevalence of sarcoptic mange (47.9\%) and tick $(25.6 \%)$ infestations, diarrhea (5.1\%) and respiratory infections (4.5\%) [11]. Observed and/or reported frequency of plant poisoning and mange infestation were higher in Gursum compared to Kebribeya district which was probably attributed to agro-ecological variations. Heavy mange and tick infestation in camel calves reflects potentially substantial direct morbidity losses as well risk of tick borne diseases. Considering availability of reasonably effective and affordable control strategies, prevailing camel calf ecto-parasite infestation challenges reflect critical gaps in animal health services and/or producers awareness

Major camel calf diseases demonstrated distinct age dependent predisposition trends. Accordingly, diarrhea, orf and plant poisoning were more common in younger ( $<6$ months) calves. In contrast, mange and tick infestation, ring worm, pox and trypanosomosis mainly affected older growing (6-12 months) calves. Newborn camel calves have little natural immunity [22]. In the face of inadequate early colustrum intake and poorly hygienic husbandry practices, camel neonates would be highly exposed to diverse environmental and contagious pathogens associated with diarrhea. Owing to absence of colustral passive immune transfer, contagious ecthema/orf most commonly affects very young animals in endemic areas. Meanwhile, introduction of lush green forages to young calves lacking well developed foregut and intestines could also predispose digestive disorders like diarrhea. Likewise, premature range grazing could force small calves (having limited browsing reach) to consume potentially poisonous lowgrowing shrubs like Lantana camara which was abundant in Gursum district. On the other hand, mange and tick infestation, ring worm and trypanosomosis were contact/vector transmitted endemic problems having chronic and progressive nature. Therefore, these conditions are likely to surface some time after young camel calves start mixing with older potential infected herd-mates and grazing in vector infested rangelands. Meanwhile, camel pox has been characterized as strong maternal passive immune transfer and transmitting by tick $(H$. dromedary) vectors [29]. Therefore, risk of infection would naturally increase when contact with potentially infected animals and/or vectors increase after maternal antibodies in circulation had dwindled.

Camel calves in the study area face different health problems including contagious and environmental infections; ecto-parasite infestation, vector borne diseases; and plant poisoning. Inadequate early colustrum feeding, poor health and hygiene management, and premature herd mixing and release to rangelands could be important epidemiological determinants. Effect of health problems could be compounded by nutritional disorders associated to premature milk restriction and forage/grazing introduction. Successful rearing of camel calves requires improved husbandry and health care practices matched to the physiological need of animals and local distribution of disease agents. This demands deeper and more comprehensive epidemiological characterization of important camel calf health problems in different agro-ecological settings.

\section{Acknowledgments}

The authors would like to thank the College of Veterinary medicine - Jigjiga University for facilitating logistic and laboratory facilities.

\section{References}

1. FAO STAT (2011) Food and Agriculture Organization of the United Nations statistical databases.

2. Abbas B, Al-Qarawi A, Al-Hawas A (2000) Survey on camel husbandry in Qassim region, Saudi Arabia: herding strategies, productivity and mortality. Mag Anim husbandry Vet Med Tropic Countries 53: 293-298.

3. Tura I, Kuria G, Walaga HK, Lesuper J (2010) Camel Breeding Management among the Somali, Sakuye, Gabbra and Rendille Pastoralists of Northern Kenya. Tropentag, Zurich, Switzerland.

4. Schwartz HJ, Dioli M (1992) The One-Humped Camel in Eastern Africa: A Pictorial Guide to Diseases, Health Care and Management. Verlag Josef Margraf, Scientific Books, Weikersheim FR, Germany.

5. Yesihak Y, Bekele T (2003) Growth pattern of one humped camel (Camelus dromedarius). Proceeding of the $11^{\text {th }}$ Annual Conference of the Ethiopian Society of Animal Production (ESAP), Addis Ababa, Ethiopia.

6. Keskes S, Ibrahim M, Tessema TS, Tamir B, Regassa F, et al. (2013) Production systems and reproductive performances of Camelus dromedarius in Somal regional state, eastern Ethiopia. J Agric Environ Int Dev 107: 243-266.

7. Tefera M (2013) The Ethiopia Camel. Haramaya University.

8. Al-Juboori A, Baker MM (2012) Studies on Common Reproductive Disorders in Dromedary Camels (Camelus dromedarius) in United Arab Emirates (UAE) Under Field Conditions. $3^{\text {rd }}$ Conference of thelnternational Societyof Camelid Researchand Development, Muscat.

9. Getahun T, Kassa B (2002) Camel Husbandry Practices in Eastern Ethiopia: The Case of Jijiga and Shinile Zones. Nomadic Peoples 6: 158.

10. Tadesse Y, Urge M, Abegaz S, Kurtu MY, Kebede K, et al. (2014) Husbandry and breeding practices of dromedary camels among pastoral communities of Afar and Somali regional states, Ethiopia. J Agric Environ Int Dev 108: 167-189.

11. Megersa B (2014) Major Diseases of Camel Calves in Borana of Southern Ethiopia. Afr J Basic Appl Sci 6: 159-165.

12. Gilbert K, (2012) A Study to Determine Factors Affecting Health and Productivity of Camel Calves in Marsabit District of Kenya, A Thesis, University of Nairobi.

13. Kuria SG, Tura I, Amboga S, Walaga HK, Lesuper J (2011) The current status of camel (Camelus dromedarius) calf management among pastoral communities of northern Kenya, Livest Res Rural Dev 23.

14. Kamber R, Farah Z, Rusch P, Hasig M (2000) The supply of newborn came foals (Camelus dromedaries) with mmunoglobulin G. Schweiz Arch Tierheilkd 142: $581-588$.

15. Save the Children-UK/SC-UK (2004) Somali Regional State, Ethiopia: Livelihood Zone (LZ) Map: Source: Field Surveys conducted by SCUK/DPPB. Food Security Monitoring and Early Warning Programme - Revised 2004 Pastoralism in Ethiopia: Its total economic values and development challenges. Project Evaluation Report: Oxfam Canada, December 2007, Addis Ababa, Pp: 1-33.

16. Walton SF, Currie D (2007) Problems in diagnosing scabies, a global disease in human and animal populations. Clin Microbiol Rev 20: 268-279.

17. Walker AR, Bouattour JL, Estrad-Pena IG, Horalk AA, Pegram RG, et al. (2003) Ticks of domestic animals in Africa: A Guide to identification of Species. Bioscience and Reports, Edinburgh, UK. pp: 262.

18. Wall R, Shearer D (1997) Veterinary Entomology. Arthropod ectoparasites of veterinary importance, Chapman and Hall, London, pp: 2-5.

19. Seifu E (2009) Analysis on the contributions of and constraints to came production in Shinile and Jijiga zones, eastern Ethiopia. J Agric Environ Int Dev 103: 213-224.

20. Awoke K, Ali SM (2015) Traditional Husbandry Practices and Major Challenge of Young Stock (Camel Calf) in Fafen Zone, Ethiopian Somali Regional State Ethiopia. J Environ Anal Toxicol 5: 321. 
Citation: Rirash AH, Wakayo BU, Abdi H (2017) Camel Calf Husbandry Practices and Health Problems in Fafem Zone, Ethiopian Somali Region. J Vet Sci Technol 8: 456. doi: 10.4172/2157-7579.1000456

Page 6 of 6

21. Farah KO, Nyariki DM, Ngugi RK, Noor IM, Guliye AY (2004) The Somali and the Camel: Ecology, Management and Economics. Anthropologist 6: 45-55.

22. Bishr AM, Magdub AB, Abuzweda ABR (2013) The Appropriate Time Required for Newborn Calf Camel to Get Optimal Amount of Colostrums Immunoglobulin ( $\operatorname{lgG}$ ) with Relation to Levels of Cortisol and Thyroxin, World Academy Sci Eng Technol 7: 03-21.

23. Njanja JC (2007) Major factors associated with high morbidity, mortality and poor performance of camel calves, kids and lambs in the Rendille and Samburu pastoral herds in Marsabit District Kenya. PhD Thesis University of Nairobi.

24. Yagil $L$ (1994) The camel in today's world: A Handbook of Camel Management. GIFRID/ Welthungerhilfe, Wageningen, The Netherlands. $74 p$.
25. Kumaresan A, Layek SS, Mohanty TK, Patbandha T, Prasad S (2012) Managing Calf Scours - A Herd health approach. Intas Polivet 13: 8-14.

26. Wilson RT (1998) Camels, the Tropical Agriculturalists (CTA). Macmillan Ltd. In: Yagil R (ed.), 1982. Camels and camel milk. FAO Animal Production and Health Paper, Food and Agriculture Organization.

27. Gluecks IV (2007) The Prevalence of Bacterial and Protozoal Intestina Pathogens in Suckling Camel Calves in Northern Kenya. Free University of Berlin, Germany.

28. Feyera T, Admasu P, Abdilahi Z, Mummed B (2015) Epidemiological and therapeutic studies of camel mange in Fafan zone, Eastern Ethiopia. Parasit Vectors 8: 612.

29. OIE Terstrial Mannual (2014) Chapter 2-9-2. Camel Pox. 